\title{
Analysis on the Relationship between the Virtual Water and Economic Development in Jing-Jin-Ji Region
}

\author{
Liu Ning ${ }^{1, a^{*}}$, Sha Jinghua ${ }^{1, b}$ and Zhang Hongliang ${ }^{2, c}$ \\ ${ }^{1}$ School of Humanities and Economic Management, China University of Geosciences, Beijing \\ ,100083, China \\ ${ }^{2}$ School of Economics and Management, Southwest University of Science and Technology, \\ Chongqing, 621000,China \\ aningzi70042@163.com, 'b shajinghua@163.com, ${ }^{\mathrm{c} 31013810 @ q q . c o m}$
}

Keywords: Jing-Jin-Ji Region, virtual water, plantation structure, fixed-effect model.

Abstract. Water shortage and irrational allocation have restricted the economic and social development of Jing-Jin-Ji region. 70 percent of water is used for agriculture, while virtual water of agriculture come up to $1854 \times 108 \mathrm{~m} 3$ which is ten times of the annual water consumption of this area. According to the principle of saving and optimal allocation, the research analyzing the effect of main agricultural products to economic growth, based on calculating ten kinds of virtual water of main agricultural products. The method is fixed effects regression model. The conclusion is as follows: Three products of milk, vegetables, dry and fresh fruit are suitable for production in Jing-Jin-Ji region because of a positive role in development of per capita GDP and low virtual water content; Three products of grain crops, meat and poultry eggs are not suitable for production in Jing-Jin-Ji region because of a negative role in development of per capita GDP and high virtual water content, while a limited amount of grain crops, meat and poultry eggs should be imported to guarantee the regional strategic security; Forest products play an important role in environmental protection and should offer subsidy to producer in spite of a negative role and high virtual water content; cotton belongs to government subsidies product and Oil products and aquatic products could be imported completely.

\section{Introduction}

Jing-Jin-Ji region is an urban agglomeration area composed of Beijing, Tianjin and Hebei province. The area of this region reaches 216 thousand square kilometers and the population reaches 100 million. Because of the regional connection, symbiotic resources, complementary economic development and the same strain of water resources, the coordinated development of Jing-Jin-Ji region outline is just enacted in 2015. The aim of outline is to change the imbalance of regional development and resource allocation, to promote the coordinated development of economy, society and resources. Water shortage and uneven allocation have been becoming one of the most serious problems of Jing-Jin-Ji region. According to the statistical yearbook, water supply of Jing-Jin-Ji region was $125 \times 108 \mathrm{~m} 3$ in 2013 , while water demand was $255 \times 108 \mathrm{~m} 3$. The demand-supply gap was $130 \times 108 \mathrm{~m} 3$ and year-on-year growth of $172 \%$ in 2013 . Furthermore, the average of demand-supply gap is $79 \times 108 \mathrm{~m} 3$ during the last ten years. Given to the above calculation, water shortage problem of Jing-Jin-Ji region is obvious. Agricultural water demand was $182 \times 108 \mathrm{~m} 3$ which is $70 \%$ of the whole year supply, while the first industry output value accounted for $4 \%$, Water resources allocation is not reasonable.

According to the Water pollution control plan enacted in 2015, the district such as Hebei province where agricultural water consumption is the major fraction of freshwater consumption should decrease planting area of water intensive crops, and save water by adjusting the agricultural planting structure. Based on previous studies, crop water consumption not only needs to consider the entity water, but also need to account the cost of virtual water. The term 'virtual water' was introduced by Tony Allan in the early 1990s. It is defined as the volume of water required to produce agricultural products, which is extended from the concept of embedded water[1]in 1993, then it is defined as the volume of water required to produce a commodity or service in 1996[2]. It is from the production point of view and quantifies virtual water as there all water used in the commodity production. The virtual water of agricultural products in Jing-Jin-Ji region was $1854 \times 108$ m3in 2013, which was ten 
times of agriculture entity water consumption. It is of great importance to control the virtual water for saving water resources of Jing-Jin-Ji region. This research analyzes that main agricultural products virtual water impact on regional economy, basing on accounting main agricultural products virtual water content in Jing-Jin-Ji region..

\section{Review of relationship between Virtual Water and economic development}

Virtual water research focused on two main themes so far. One is virtual water content calculation, the other is virtual water trade. The relationshipbetween virtual water and economic development is an important topicbased on the virtual water content calculation. At the beginning, the virtual water calculation object focused on farm crops and livestock products[3-6], that is farm crops productscontent, livestock products content and regional agriculture virtual water total content, whereafter, the virtual water calculation object extended to all the commodity. Tian accounted the China's wood forest products virtual water[7].Economic elements, resources elements and environmental elements are very important influencing factors of virtual water content and virtual water trade[8-11]. Resources elements such as population, plowland number and applying quantity of chemical fertilizer have high matching rate with virtual water. Environmental elements such as soil and water loss have low matching rate with virtual water. Economic elementssuch as GDP have a declining matching rate with virtual water.On the contrary, Virtual water plays an important role on the economic development and adjustment of industrial allocation. Maksud Bekchanov researched the role of virtual water for Uzbekistansustainable economic restructuring by using the input-output method, the conclusion is that developing agro-processing industries and the livestock sector rather than relying on the production of raw agricultural commodities such as cotton, wheat, and rice provides more sustainable economic development in Uzbekistan[12].Research carried on by Samir Suweisfindsthat virtual water controlled demographic growth and population of nations[13]. Zou put forwards the regional virtual water content represents china's agricultural industry distribution, and optimizing the layout of agricultural production by calculate matching rate betweenthe virtual water contentand regional economic. In conclusion, Virtual water is closely associated with regional economic development, and it is reasonable to promote agricultural planting structure and water resources allocation restructuringby measuring the main agricultural virtual water impact on economic growth.

\section{Data sources}

According to China statistical yearbook classification, the main agricultural products in Jing-Jin-Ji region are farm products, forestry products, husbandry products and fishing products. Farm products include grain (such as rice, winter wheat, corn, beans and tubers), cotton, oil plants, vegetable and fruit. Husbandry products include pork, beef, mutton, poultry meat, egg and milk. Fishing products mainly include fresh-water fish. Forestry products include afforestation of barren hills and culture of seedling. Given to the different planting conditions, Hebei province additionally includesmillet, Chinese sorghum, tobacco and hemp.

There are two types of virtual water calculation method. One is calculation according to separate products[15], the other is according to different kinds of products[16].Both of them are Life cyclecalculation method and are based on the Penman-Monteith Method developed by FAO. The Penman-Monteith Method is used to calculate agricultural products virtual waterper unit mass. Main agricultural products virtual water equal to agricultural products virtual waterper unit massmultiply by agricultural products production. The data of agricultural products production is from China Statistical Yearbook (1995-2014), Beijing Statistical Yearbook (1995-2014), Tianjin Statistical Yearbook (1995-2014) and Hebei Statistical Yearbook (1995-2014). The data of agricultural products virtual water per unit mass is from previous studies. Sun[8] and Ma[18]figure out main agricultural products virtual waterper unit mass of China. Hoekstra A Y[19] figure out livestock products of China. Tian[7]figure out wood forest products virtual water. Finally, we obtain main 
agricultural products virtual waterper unit mass of Jing-Jin-Ji region(Tab.1). The data we get above is in line with the panel data form, so panel data model is applicable.

Tab.1 Main agricultural products virtual waterper unit mass of Jing-Jin-Ji region

\begin{tabular}{ccccc}
\hline industry & products & Beijing & Tianjin & Hebei \\
\hline & winter wheat & 1.23 & 1.25 & 1.065 \\
& rice & 1.4 & 1.19 & 2.185 \\
& corn & 0.84 & 0.85 & 0.817 \\
& millet & -- & -- & 0.93 \\
& Chinese sorghum & -- & -- & 1.343 \\
Farm products & beans & 2.24 & 3.73 & 1.08 \\
& tubers & 0.7 & 1.07 & 1.2 \\
& cotton & 5.22 & 4.4 & 5.5 \\
& oil plants & 1.5 & 1.5 & 2.2 \\
& tobacco & -- & -- & 2.76 \\
& hemp & -- & -- & 2.185 \\
& vegetable & 0.24 & 0.13 & 0.1 \\
& fruit & 0.55 & 1.38 & 1.5 \\
\hline \multirow{4}{*}{ husbandry } & pork & 3.7 & 3.6 & 3.6 \\
products & beef & 19.99 & 19.99 & 18.99 \\
& mutton & 18.01 & 18.01 & -- \\
& poultry meat & 2.7 & 3.11 & 8.65 \\
Fishing & egg & 8.65 & 8.65 & 2.2 \\
products & milk & 2.2 & 2.2 & 3.11 \\
\hline Forestry & fresh-water fish & 3.11 & 3.11 & \\
products & afforestation ( & & & 85865.1 \\
\hline
\end{tabular}

Notice: Beijing and Tianjin do not product millet, Chinese sorghum, tobacco and hemp.

\section{Model construction and test}

\section{Model construction}

Panel data model usually include fixed-effect model, random-effect model and mixed-effects model. The general expressions for the three model is as follows.

$\ln _{\mathrm{il}}=\mathrm{C}+\beta_{\mathrm{it}} \sum \ln \mathrm{X}_{\mathrm{il}}$

Where $Y_{i}$ is dependent variables, this study selects GDP per capita. $X_{i 1}$ is independent variables, these are ten agricultural products virtual water in Jing-Jin-Ji region. "i" is sectional data, and this study include Beijing, Tianjin and Hebei. " $t$ " is time-series data from 1994 to 2013. C is constant. $\beta_{11}$ is regression coefficient vector. 


\section{Unit Root Test}

Tab.2 Unit root test results

\begin{tabular}{ccccccccc}
\hline & \multicolumn{9}{c}{ Madfuller test } & & \multicolumn{2}{c}{ Hadrilm test } \\
\cline { 2 - 5 } & $\begin{array}{c}\text { lag } \\
\text { phase }\end{array}$ & $\begin{array}{c}\text { difference } \\
\text { order }\end{array}$ & MADF & $\begin{array}{c}\text { critical value } \\
(5 \%)\end{array}$ & stationarity & & $\begin{array}{c}\text { difference } \\
\text { order }\end{array}$ & stationarity \\
Y & 1 & 2 & 123.411 & 49.619 & stationary & & stationary \\
X1 & 1 & 1 & 56.797 & 45.195 & stationary & & 1 & stationary \\
X2 & 1 & 1 & 53.249 & 45.195 & stationary & & 1 & stationary \\
X3 & 1 & 1 & 52.654 & 45.195 & stationary & & 1 & stationary \\
X4 & 1 & 2 & 146.125 & 49.619 & stationary & & 2 & stationary \\
X5 & 1 & 1 & 48.547 & 45.195 & stationary & & 2 & stationary \\
X6 & 1 & 1 & 78.018 & 45.195 & stationary & & 1 & stationary \\
X7 & 1 & 0 & 88.321 & 41.700 & stationary & & 2 & stationary \\
X8 & 1 & 2 & 71.858 & 49.619 & stationary & & 2 & stationary \\
X9 & 1 & 0 & 43.348 & 41.700 & stationary & & 1 & stationary \\
X10 & 1 & 2 & 118.394 & 49.619 & stationary & & 1 & stationary \\
\hline
\end{tabular}

This study adopts Madfuller test and Hadrilm test to test stationarity of time series data.(1)Madfuller test:H0 is all 3 time series in the panel are I(1) processes, if you reject the null hypothesis that at least one sequence is smooth. (2) Hadrilm test: H0 is all 3 time series in the panel are smooth, if you reject the null hypothesis thatat least one sequence is not smooth.

In the Madfuller test, all the lag time series is 1 . At least one sequence of X7 and X9 is smooth in original data sequence, and at least one sequence of X1, X2, X3, X5 and X6is smooth in lag time 2. In the Hadrilm $r$ test, at least one sequence of X1, X2, X3, X6, X9 and X10 is not smooth in lag time 1, and at least one sequence of $\mathrm{Y}, \mathrm{X} 4, \mathrm{X} 5, \mathrm{X} 7$ and $\mathrm{X} 8$ is not smooth in lag time 2. Combining with two kinds of results, Time series of X1-X10 are stationary under the condition of difference order(Tab.2).

\section{Model test}

This study adopts Wald F test, B-Ptest and Hausman test to distinguish the difference of fixed-effect model, random-effect model and mixed-effects model. (1)Wald F test: H0 is bit= b0, if you reject the null hypothesis that we should adopt fixed-effect model; (2)B-P test: $\mathrm{H} 0$ is bit= 0 , if you reject the null hypothesis that we should adopt random-effect model; (3)Hausman test: H0 is COV ( Xit , bit ) $=0$, if you reject the null hypothesis that we should adopt fixed-effect model. According to the test results, this study adopts the fixed-effect model to estimate the panel data(Tab.3).

Tab. 3 Statistical tests

\begin{tabular}{llll}
\hline test & detection value & Pvalue & Preferred \\
\hline Wald test & 24.31 & 0.0000 & fixed-effect model \\
B-P test & 894.88 & 0.0000 & random-effect model \\
Hausman test & 49.46 & 0.0000 & fixed-effect model \\
\hline
\end{tabular}

\section{Regression analysis of fixed-effect model}

According to descriptive statistics, the virtual water content of egg, afforestation, grain and meat are highest, and the annual virtual water content are more than 100 billion cubic meters. The annual virtual water content of fruit is 41 billion cubic meters. The annual virtual water content of vegetable and milk are more than 20 billion cubic meters. The annual virtual water content of fresh-water fish is 18 billion cubic meters. The annual virtual water content of cotton and oil plants are 18 billion cubic meters. The distribution of ten agricultural products virtual water content reflect water resources allocation situation and crops industry layout in Jing-Jin-Ji region. Additionally, it is controversial to 
make water resources policy just rely on virtual water content[20], so this research also analyzes the effect of main agricultural products to economic growth as the basis of agricultural planting restructuring.

Regression analysis shows $\mathrm{R}^{2}=0.9642$. All the $\mathrm{X} 1-\mathrm{X} 8$ are through the $\mathrm{t}$ value test within the $95 \%$ confidence interval. X10 passes the $\mathrm{t}$ value test the $90 \%$ confidence interval. X9 do not pass the $\mathrm{t}$ value test.In addition, thatF test is significant shows equation simulation effect is good. The regression equation we get is as follows(Tab.4).

$$
\begin{aligned}
& \operatorname{Ln} Y=10.9-0.34 \operatorname{Ln} X 1-0.16 \operatorname{Ln} X 2-0.76 \operatorname{LnX} 3+0.97 \operatorname{Ln} X 4+0.18 \operatorname{Ln} X 5-0.33 \operatorname{Ln} X 6-0.39 \operatorname{Ln} X 7+ \\
& 0.49 \operatorname{Ln} X 8-0.97 \operatorname{Ln} X 10
\end{aligned}
$$

Vegetable, milk and fruit have a positive effect on Per Capita GDP, where vegetable has the strongest positive effect, and milk and fruit are subsequent. Virtual water of vegetable each additional unit, the per capita GDP growth rate was $97 \%$. Virtual water of milk and fruit each additional unit, the per capita GDP growth rate was $49 \%$ and $18 \%$ separately. Grain, cotton, oil plants, meat, egg and afforestation have a negative effect on Per Capita GDP, where oil plants has the strongest negative effect, and egg, grain and meat are subsequent. Virtual water of oil plants each additional unit, the per capita GDP growth rate was $-75 \%$.Virtual water of egg, grain and meat each additional unit, the per capita GDP growth rate was $-38 \%,-34 \%$ and $-33 \%$. Besides that, cotton and afforestation also have limited negative effect on Per Capita GDP, and virtual water of cotton and afforestation each additional unit, the per capita GDP growth rate was $-16 \%$ and $-9 \%$ respectively.

Tab.4 Regression result

\begin{tabular}{lccc}
\hline & LnY & coefficient & t \\
\hline LnX1 & -0.34 & 2.86 & P value \\
LnX2 & -0.16 & 5.43 & 0.006 \\
LnX3 & -0.76 & -6.70 & 0.000 \\
LnX4 & 0.97 & 3.87 & 0.000 \\
LnX5 & 0.19 & 3.63 & 0.000 \\
LnX6 & -0.33 & -2.54 & 0.015 \\
LnX7 & -0.39 & -3.38 & 0.001 \\
LnX8 & 0.49 & 5.72 & 0.000 \\
LnX9 & -0.06 & -0.62 & 0.535 \\
LnX10 & -0.97 & -1.69 & 0.097 \\
cons & 10.89 & 13.77 & 0.000 \\
& $\mathrm{R}^{2}($ within $)=0.9642$ & & \\
& $\mathrm{~F}=24.31$ Prob $>\mathrm{F}=0.0000$ & & \\
\hline
\end{tabular}

\section{Conclusions}

The present situation and restructuring direction of agricultural planting structure in Jing-Jin-Ji region is as follows.

(1) Vegetable, milk and fruit are suitable for production in Jing-Jin-Ji region. Because of the positive effect on Per Capita GDP and less of virtual water, three products not only is beneficial to improve the level of GDP per capita, but also save water resources.

(2) Because of the negative effect on Per Capita GDP and cost of virtual water, three products of grain, meat and egg are not suitable for production in Jing-Jin-Ji region. Given to be closely related to residents, three products have important strategic security status. It necessary to limitedly reduce the local production and increase imports from the surrounding area and international trade, while maintaining regional safety.

(3) Forestry products play an important role to protect the ecological environment, though it has a week negative effect on Per Capita GDP and cost of virtual water. So the restructuring direction of forestry products is to increase subsidies for forestry industry, to increase economic forest tree planting proportion for improving the income of planter, to increase the coniferous forest planting proportion for saving water. 
(4) Cotton virtual water is less, but has a week negative effect on Per Capita GDP. So the restructuring direction of cotton is to develop cotton processing industries for increasing the income of peasants.

(5) Because of the heaviest negative effect on Per Capita GDP and be difficult to improve the economic benefit by large-scale production, oil plants could completely import from Shandong peninsula and Liaodong peninsula.

(6) Fishing products have no significant impact on the economy, combining with the current situation that the river is dying up and wetland is shrinking. So the restructuring direction of fishing products is to reduce the local production and increase imports from the surrounding area.

\section{References}

[1] J A Allan. Fortunately there are substitutes for water otherwise our hydro-political futures would be impossible [R]. Priorities for Water Resources Allocation London: ODA, 1993. 13-26.

[2] J A Allan. Water in the Middle East: Legal and Commercial Issues [M]. Edited with C Mallat and Contributed, London, Tauris Academic Press, 1996:360-677.

[3] A K CHAPAGAIN, A Y Hoekstra. Virtual water trade: a quantification of virtual water flows between nations in relation to international trade of livestock and livestock products, 2003. 49-76

[4] Guodong Cheng. Virtual water-A strategic Instrument to Achieve Water Security[J]. Bulletin of Chinese Academy of Sciences, 2003, 18(4):260-265(in Chinese).

[5] Zhongmin $\mathrm{Xu}$, Aihua Long, Zhiqiang Zhang. Virtual water Consumption Calculation and Analysis of Gansu Province in 2000[J]. ACTA Geographic Sinica, 2003, 58(6):861-869(in Chinese).

[6] Xinhua Wang. A Study of Simulated Water Trade in the Four Provinces in Central China[J]. Journal of South Huanan Agricultural University(Sociaal Science Edition), 2004, 3(3):33-38(in Chinese).

[7] Minghua Tian, Cheng Liu, Qiujie Gao. Initial Estimates of Content and Trade of Virtual Water by Wood Forest Products in China. Journal of Beijing Forestry University (Sociaal Science), 2012, 11(2):82-88(in Chinese).

[8] Caizhi Sun, Lei Zhang. Changes in Spatial and Temporal Differences of Agricultural Product Virtual Water Versus Cultivated Land in China[J].Resources Science, 2009, 31(1):84-93(in Chinese).

[9] Caizhi Sun, Yuyu Liu, Lei Zhang. Analysis on the Spatial-Temporal Matching of Crops Virtual Water Versus Resources-Environment-Economy Factors in China[J].Resources Science, 2010, 32(3):512-519(in Chinese).

[10] Hongmei Liu, Guojun Li, Keqiang Wang. A Study on the Determinants of the Agricultural Virtual Water Trade between China and other Countries[J]. Management world, 2010, (9):76-87(in Chinese).

[11] Hongmei Liu, Guojun Li, Keqiang Wang. Analysis on the Determinants of the Agricultural Virtual Water of China based on the gravity model[J]. Chinese Rural Economy, 2011, (5):21-32(in Chinese).

[12] Bekchanov, Maksud and Bhaduri, Anik and Lenzen, Manfred and Lamers, P.A John., The Role of Virtual Water for Sustainable Economic Restructuring: Evidence from Uzbekistan, Central Asia (June 1, 2012). ZEF- Discussion Papers on Development Policy No. 167.

[13] Samir Suweis, Andrea Rinaldo, Amos Maritan, Virtual water controlled demographic growth of nations[P], physics.soc-ph, 2013-06-29. 
[14] Jun Zou, Shuangtong Fu, Yurong Yang. Spatial Optimization of Agricultural Regions Under the Background of Virtual Water Strategy.Resources and Environment in the Yangtze Basin[J], 2010, (12):1427-1432(in Chinese).

[15] A Y Hoekstra Virtual Water Trade: Proceedings of the International Expert Meeting on Virtual Water Trade[R]. Delft , Netherlands: IHE , 2003:13-23 .

[16] D Zimmer, D Renaul. Virtual water in food production and global trade: review of methodological issues and preliminary results. In: Hoekstra A Y (ed.) virtual Water Trade; (No.12). IHF Delft; 2003. 93-107

[17] R G Allen, L S Pereira, D Raes et al. Crop evapotranspiration: guidelines for computing crop water requirements. FAO Irrigation and Drainage Paper 56. Rome: 1998, (2): 8.

[18] Chao Ma, Changxin Xu, Guiliang Tian. The Virtual Water Flow in China 's foreign Trade of Agricultural Products[J]. Resources Science, 2011, 33(4):729-735(in Chinese).

[19] A K Chapagain, A Y Hoekstra. Virtual water trade: A quantification of virtual water flows between nations in relation to international trade of livestock and livestock products[C]//Virtual water trade. Proceedings of the international expert meeting on virtual water trade. 2003.

[20] D Wichelns. Virtual Water: A Helpful Perspective, but not a Sufficient Policy Criterion[J]. Water Resources Management, 2010, 24(10):2203-2219. 